\title{
A foldable high transparent fluorinated polyimide (HFBAPP/6FDA) film material for transparent flexible substrate
}

\author{
Chuanhao Cao ${ }^{1}$ (D), Lizhu Liü ${ }^{1,2 *}$ (iD) and Xiaorui Zhang ${ }^{1,2}$ \\ ${ }^{1}$ School of Materials Science and Engineering, Harbin University of Science and Technology, Harbin, \\ China \\ ${ }^{2}$ Key Laboratory of Engineering Dielectric and Its Application, Harbin University of Science and \\ Technology, Ministry of Education, Harbin, China \\ *Corresponding author: mrliu_hust@163.com
}

\begin{abstract}
Flexible transparent substrate materials, which was able to withstand high dynamic strain, in contrast to traditional substrate materials. A flexible and transparent material with advantages including transparency, stable size, and excellent corrosion and electrical resistance was provided. The polyimide(PI) film was prepared by introducing a structure with a high content of $\mathrm{F}$ atom and a fine optimization process to enhance the various properties of the film. However, the properties of the films were optimized effectively by gradient vacuum and secondary dissolution so that the film had a transmittance at $400 \mathrm{~nm}$ of $82 \%$. The films with low dielectric constant and low dielectric loss represent the breakdown strength of $202 \mathrm{kV} / \mathrm{mm}$. The glass transition temperature of the film was $267^{\circ} \mathrm{C}$, and the thermal expansion coefficient was $35 \mathrm{ppm} / \mathrm{k}\left(30^{\circ} \mathrm{C} \sim 270{ }^{\circ} \mathrm{C}\right)$, indicated outstanding thermal dimensional stability. Therefore, this polyimide film was an optoelectronic device with extremely high application potential on the folding mobile phone and the PI film is the finest materials of screen.
\end{abstract}

Keywords: transparent PI, transmittance, insulation, thermal performance, dielectric properties.

How to cite: Cao, C., Liu, L., \& Zhang, X. (2021). A foldable high transparente fluorinated polyimide (HFBAPP/6FDA) film material for transparent flexible substrate. Polímeros: Ciência e Tecnologia, 31(1), e2021008. https://doi. org/10.1590/0104-1428.10520

\section{Introduction}

Transparent flexible substrate materials were capable of bending deformation, compared with traditional glass substrate materials. In recent years, the demand and technical requirements of the transparent flexible substrate in the flexible display screen and other fields were increasing ${ }^{[1-4]}$. A new replacement of glass substrate material was provided by PI film, which was good at transparency, mechanical strength, corrosion resistance, heat resistance.

With the creasing of technology, enterprises were not satisfied with the status quo that grow a large-scale market for transparent flexible materials ${ }^{[5,6]}$. Hitherto, the key issue of the high transparent polyimide included high optical transmittance(TR) $)^{[7-9]}$ and low yellow value ${ }^{[10,11]}$. It was well known that polyimide was generally shown to be brown yellow and caused TR to be lower. A high yellow value led to the bad vision and the film unable to be used on a large scale. Stretchability, electrical and thermal stability under mechanical deformation were new essential criteria because transparent films need to be applicable to next-generation material. Thus far, thin transparent polyimide film had served as an ideal choice for because of good resistance to shockresistant to many chemicals and good heat resistance ${ }^{[12-15]}$.

In the past few decades, new PI had been grown by excellent performance as film material, such as aliphatic $\mathrm{PI}^{[16,17]}$, aromatic $\mathrm{PI}^{[18,19]}$, and other $\mathrm{PI}^{[20,21]}$.Imposing the conjugate plane structure or polar structure on the PI film was an essential method in principle. The aliphatic PI was a better compared with aromatic PI that was attributed to the molecular weight.

Transparent properties were considered the fatal flaw that limited the PI film qualities's application in the flexible screen application field. The traditional aromatic benzene type PI was usually brownish yellow and low light transmittance, which was mainly due to the strong charge-transfer complex (CTC $)^{[22]}$ formed between aromatic dianhydride and aromatic diamine and some dark functional groups were produced during thermoimination. Therefore, the surface of PI film had a certain orientation structure by introducing F group ${ }^{[23-26]}$, alicyclic polyimides ${ }^{[27-29]}$ and so on into the PI system. Studies had shown that the introduction of orientation structure could effectively eliminate the CTC effect within the molecule, and the introduction of macrogroup side groups could effectively eliminate the CTC effect between molecules. ${ }^{[30,31]}$ The solvent contains amides, which 
were prone to oxidation in the heating process to make the film darker. A gradient vacuum method was developed, which could effectively remove the influence of solvent without affecting the flowability of PAA glue soluting and the performance of PI film.

In this paper, a transparent material was provided by PI-HFBAPP/6FDA film. This transparent film would not be corroded and deformed by chemical agents and had good transparency. The orientation of the folding screen would not affect the visual experience of the reader. By adjusting the polymer structure and optimizing the process especially, the film with high visible light transmittance was prepared on the premise of ensuring the film performance. Thus, this film had great development space in the market potential in the future.

\section{Experimental Section}

\subsection{Experiment materials}

Dimethylacetamide(DMAC) was purchased from Tianjin Fuyu Fine Chemical Co., Ltd. 4,4'-(Hexafluoroisopropylidene) diphthalic anhydride(6FDA) was purchased from Wuhan lullaby pharmaceutical chemical Co., Ltd, the purify was 99\%. 2,2-Bis[4(4-aminophenoxy)phenyl]-hexafluoropropanane(HFBAPP) was purchased from Shanghai Macklin Biochemical Co., Ltd, the purify was 99\%. 4,4-oxydianiline(ODA) was purchased from Sinopharm Group Chemical Reagent Co., Ltd. 3,3',4,4'-biphenyl tetracarboxylic dianhydride(PMDA)
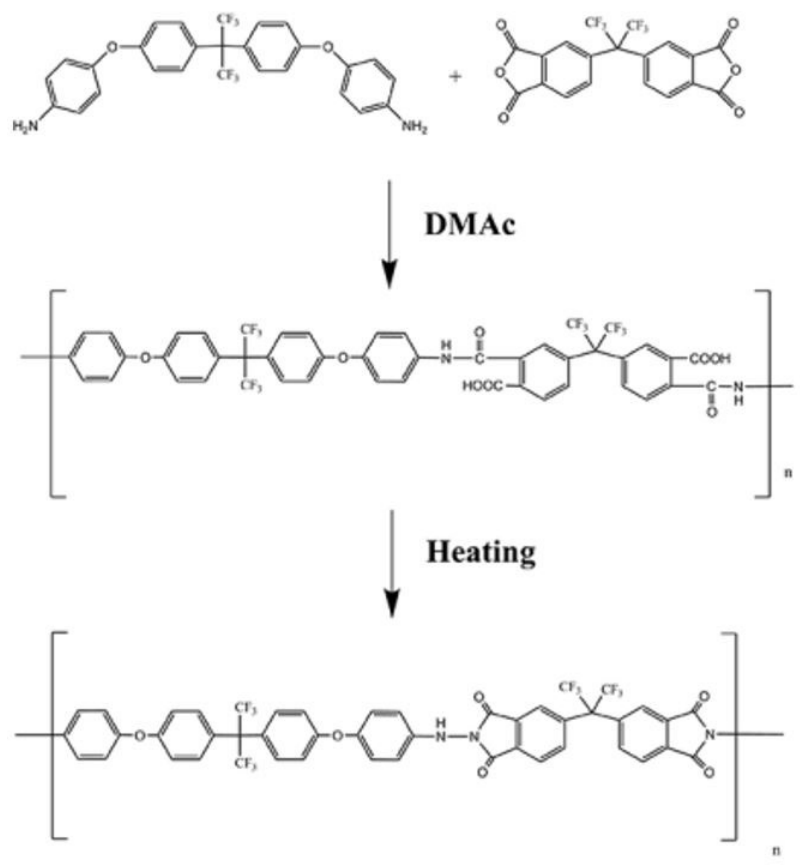

was purchased from Shanghai Macklin Biochemical Co., Ltd. All the chemicals were analytical grade reagents that were commercially available and were used without further purification.

\subsection{Experimental Procedure}

The reaction equation of HFBAPP as diamine monomer, 6FDA as dianhydride monomer was taken as an example. The reaction equation of the polymerization was shown in Figure 1.

Polyimide films were synthesized using the dianhydride 6FDA or PMDA, the diamines HFBAPP or ODA in the polar aprotic DMAc, as shown in Figure 1. The film preparation of PI-HFBAPP/6FDA was taken as a representative to illustrate the detailed procedures. The reaction flow chart of PI-HFBAPP/6FDA Film was shown in Figure 2.

By using ice-water mixing bath and nitrogen protect reaction process, HFBAPP(1.985 g, 0.03828mol) was added to DMAC $(15 \mathrm{ml})$ solvent and stirred slowly until completely dissolved. 6FDA(1.701 g, 0.003829mol) was added into the reaction system six times. The time interval for each addition of monomers was 15 minutes and added a monomer in an amount half as small as it was left. Stirring continued for 2 hours after the average viscous molecular weight climbed.

The polymer was transfer into a small beaker and the beaker was placed in a vacuum box. Then the air was extracted from the vacuum box so that the gel did not contain bubbles.
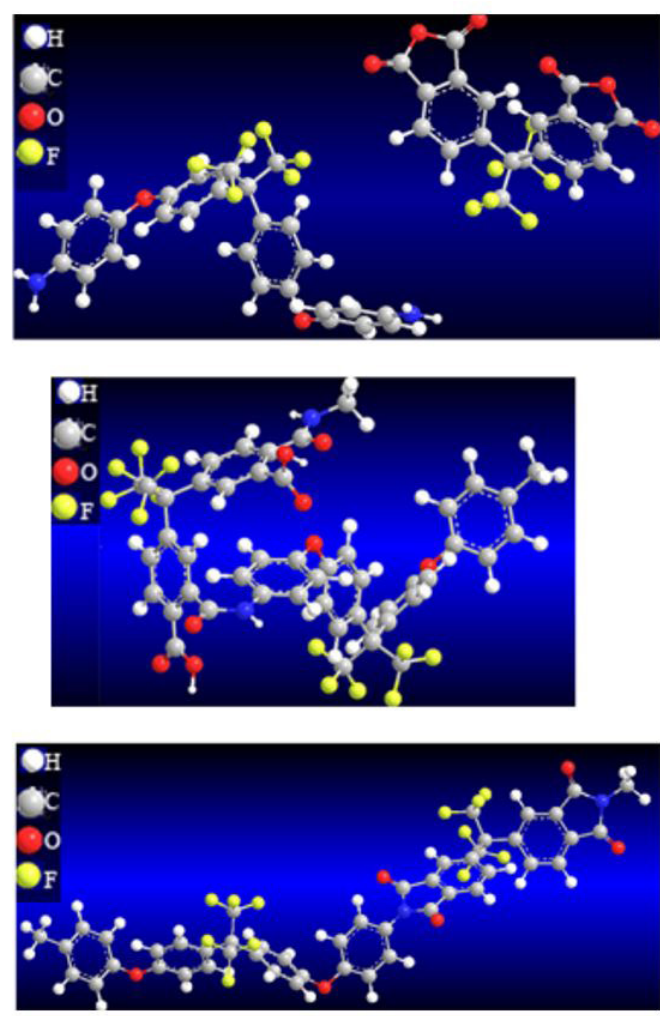

Figure 1. Preparation of PI-HFBAPP/6FDA Film. 
After cleaning the glass plate, the standing polyamic acid(PAA) was poured onto the glass plate and spread with a scraper of a certain thickness. The size of the glue film was $20 \mathrm{~cm} \times 25 \mathrm{~cm}$ and the final formed thickness of the film was $10 \mu \mathrm{m} \sim 50 \mu \mathrm{m}$.

The film was put into the oven, and the removal of solvents from the film was carried out by a gradient vacuum. As a consequence, the treated film would avoid oxidation. The specific process was shown in Table 1 .

The film was put into the oven and the thermal imidization of the film was carried out by gradient heating. The specific process was shown in Table 2 .

\section{Measurement}

The transmittance of the film and the different PI film proportions were analyzed by the UV-visible spectrophotometer of Shimadzu UV-2450. Test conditions: the wavelength was $600-250 \mathrm{~nm}$ and the sample size was $20-30 \mathrm{~mm}$.
The Bruker-EQUINOX 55-type Fourier transform infrared spectrometer manufactured by Germany was used to attenuate the total reflection infrared attachment. The polyimide film was characterized. The test condition was that the resolution was $4 \mathrm{~cm}^{-1}$, the scanning time was 16 times of the sample to be tested, the background was scanned 16 times, the delay time was $10 \mathrm{~s}$, and the test range was $500-4000 \mathrm{~cm}^{-1}$.

The dimensional stability of the films wares using by L75 $\mathrm{Pt}$ vs/VD vertical mode thermal dilatometer. Heating interval $0 \sim 270^{\circ} \mathrm{C}$, heating rate $5^{\circ} \mathrm{C} / \mathrm{min}$. The glass transition temperature and storage modulus of the PI films were measured by the dynamic mechanical analysis(DMA). All test samples were rectangular, with a length of $20 \mathrm{~mm}$ and a width of $8 \mathrm{~mm}$.

The dielectric constant and dielectric loss of the PI film was tested by an Alpha-a-type broadband dielectric spectrometer manufactured by Novocontrol Company of Germany.

The breakdown strength of the PI film was measured by using the HT-5/20 breakdown voltage tester developed by the Guilin Electrical Equipment Scientific Research Institute.
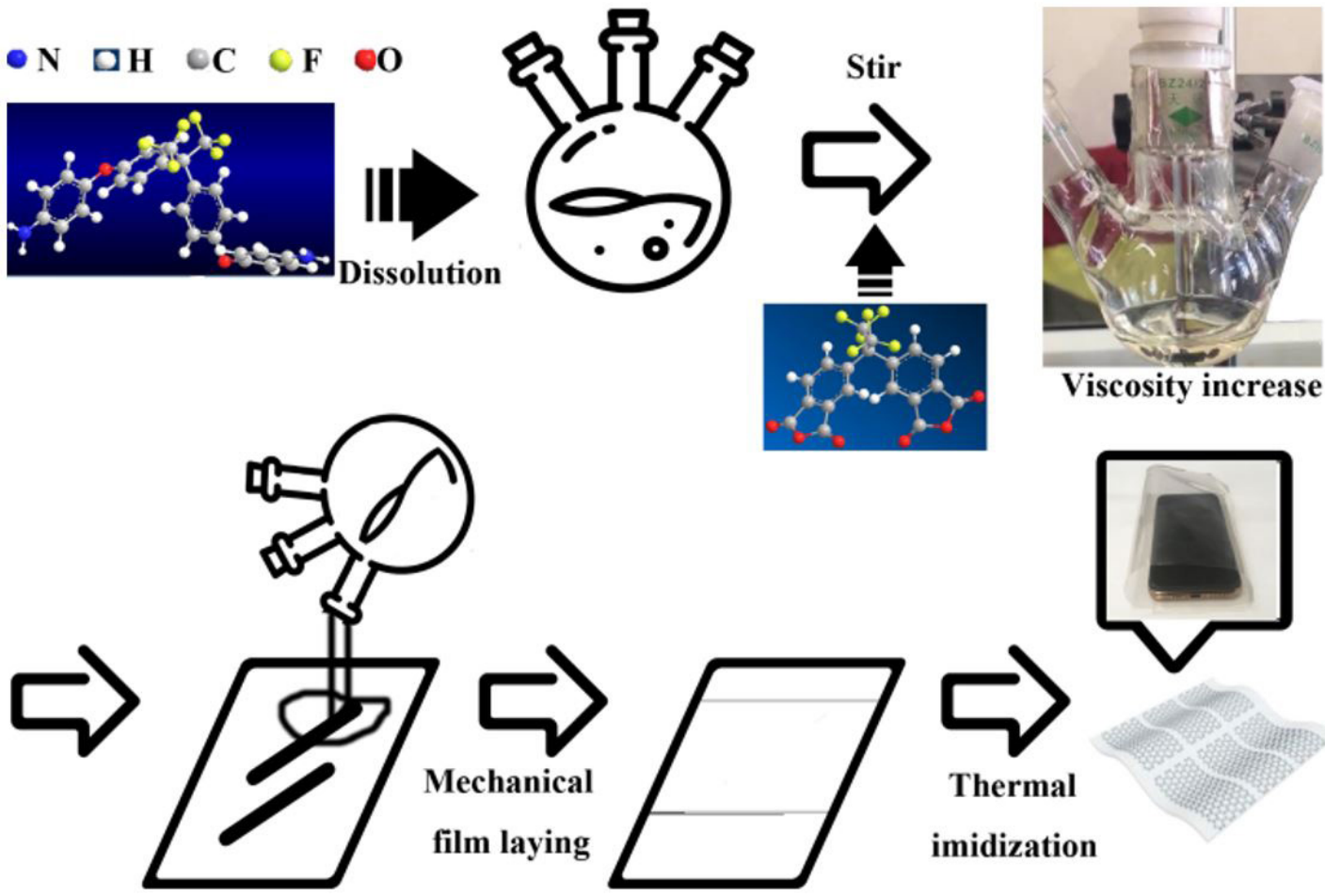

Viscosity increase

Figure 2. Reaction flow chart of PI-HFBAPP/6FDA Film.

Table 1. Gradient vacuum process.

\begin{tabular}{lcccccccccc}
\hline \multicolumn{1}{c}{ Stage } & A & B & C & D & E & F & G & H & I \\
\hline Time $/$ min & $\mathbf{1 0}$ & $\mathbf{2 0}$ & $\mathbf{1 0}$ & $\mathbf{1 0}$ & $\mathbf{2 0}$ & $\mathbf{2 0}$ & $\mathbf{2 0}$ & $\mathbf{2 0}$ & $\mathbf{3 0}$ \\
Vaccum $/$ 1atm & $\mathbf{0 . 4}$ & $\mathbf{0}$ & $\mathbf{0 . 5}$ & $\mathbf{0 . 6}$ & $\mathbf{0}$ & $\mathbf{0}$ & $\mathbf{0 . 7}$ & $\mathbf{0 . 7}$ & $\mathbf{0}$ \\
Temperature $/{ }^{\circ} \mathrm{C}$ & $\mathbf{8 0}$ & $\mathbf{8 0}$ & $\mathbf{8 0}$ & $\mathbf{8 0}$ & $\mathbf{8 0}$ & $\mathbf{1 0 0}$ & $\mathbf{1 0 0}$ & $\mathbf{1 2 0}$ & $\mathbf{1 2 0}$ \\
\hline
\end{tabular}

Table 2. Thermoimidization gradient heating schedule.

\begin{tabular}{ccccccccccccc}
\hline Temperature $/{ }^{\circ} \mathrm{C}$ & $\begin{array}{c}\text { Climb } \\
\text { to } 80\end{array}$ & 80 & $\begin{array}{c}80 \text { to } \\
120\end{array}$ & 120 & $\begin{array}{c}120 \text { to } \\
160\end{array}$ & 160 & $\begin{array}{c}160 \text { to } \\
200\end{array}$ & 200 & $\begin{array}{c}200 \text { to } \\
250\end{array}$ & 250 & $\begin{array}{c}250 \text { to } \\
300\end{array}$ & 300 \\
\hline Time/min & 15 & 45 & 10 & 20 & 10 & 20 & 10 & 20 & 10 & 20 & 10 & 20 \\
\hline
\end{tabular}




\section{Result of discussion}

\subsection{FTIR characterization}

The chemical structures of the pure PI film and PI-vacuum treatment/secondary film formation were confirmed by FTIR spectroscopy, and it was shown in Figure 3.

As a consequence, there were 6 characteristic absorption peaks of polyimide films at $1787 \mathrm{~cm}^{-1}, 1729 \mathrm{~cm}^{-1}, 1600 \mathrm{~cm}^{-1}$,

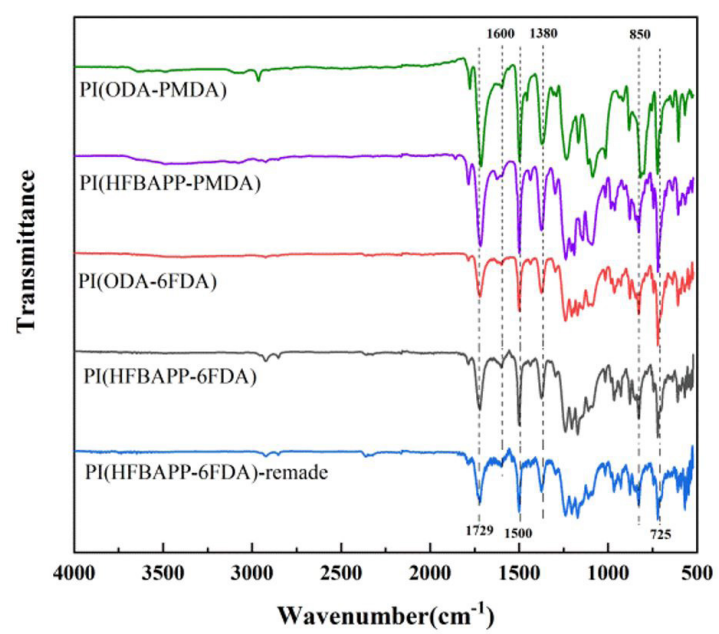

Figure 3. Infrared spectrum of pure PI film and PI film after Process Optimization.
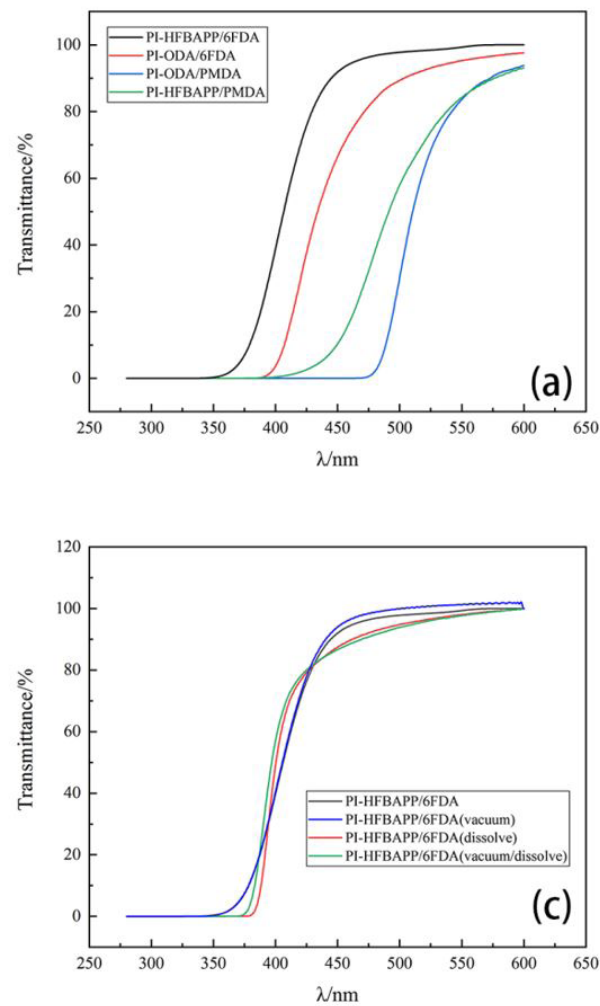

$1500 \mathrm{~cm}^{-1}, 1380 \mathrm{~cm}^{-1}, 850 \mathrm{~cm}^{-1}$, where $1787 \mathrm{~cm}^{-1}$ corresponded to the asymmetric expansion vibration of $\mathrm{C}=\mathrm{O}$, and the $1729 \mathrm{~cm}^{-1}$ corresponded to the $\mathrm{C}=\mathrm{O}$ symmetric expansion vibration. Compared with ordinary PI, the carbonyl stretching vibrations on the fluorinated PI rings moved toward higher wavenumbers. It was due to the inducing effect of the trifluoromethyl group that made the carbonyl double bond enhance and the frequency of stretching vibration increase. The peaks at $1600 \mathrm{~cm}^{-1}$ corresponded to $\mathrm{N}-\mathrm{H}$ flexural expansion vibration. The peaks at $1500 \mathrm{~cm}^{-1}$ and $850 \mathrm{~cm}^{-1}$ corresponded to the vibration of the benzene ring skeleton. The absorption peak at $1380 \mathrm{~cm}^{-1}$ represented the symmetric contraction vibration of the $\mathrm{C}-\mathrm{N}$, and the $725 \mathrm{~cm}^{-1}$ corresponded to the bending vibration of the $\mathrm{C}=\mathrm{O}$. These characteristic peaks were consistent with the standard peak positions of the PI in Figure 3, indicating the presence of PI structure and characterizing the PI structure. From Figure 3 that the change of process does not change the structure of the polymer, which could be proved by the fact that there was no difference between line 4 (PI-HFBAPP/6FDA) and line 5 (PI-HFBAPP/ 6FDA-remade).

\subsection{Characterization and optoelectronic properties}

The optical performance of CPI films was shown in Figure 3. Because of the flatness of coating and PAA glue soluting could be naturally leveled. The CPI films were uniformly distributed on the glass substrate and separated breezily. Four kinds of films to meet different production requirements were prepared, and the transmittances were characterized. As shown in Figure 4a, several kinds of CPI
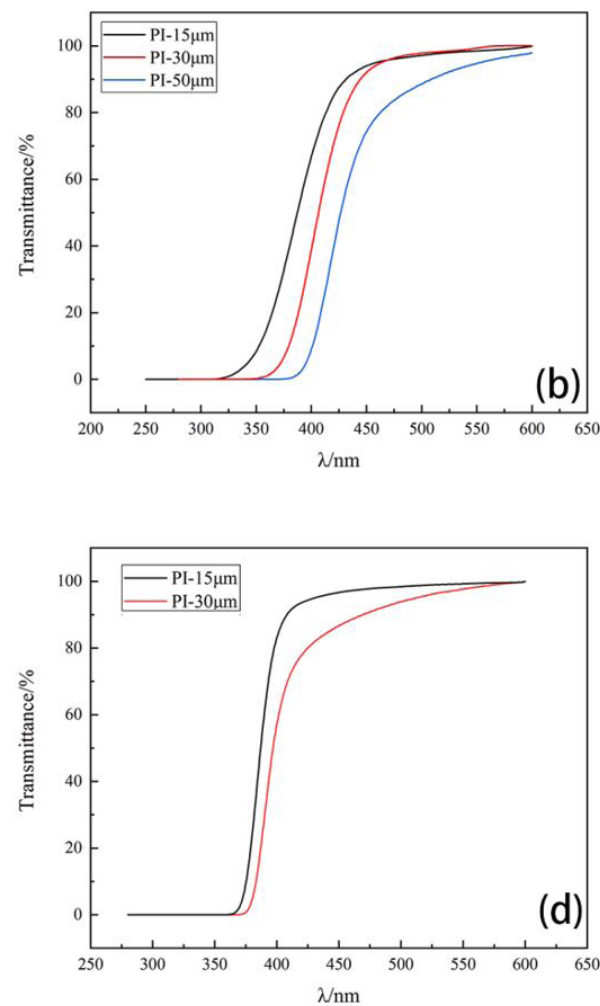

Figure 4. Transparent of PI composite films with different preparation process. (a)Transmittance of different monomers PI (b)Different thickness transmittance of PI-HFBAPP/6FDA (c)Effect of technology on the transmittance of PI (d)Optimization of thin film transmittance. 
films exhibit a high transmittance. The $341 \mathrm{~nm}$ was UV cutoff wavelength of pure PI-HFBAPP/6FDA, it was the least of PI films prepared from different monomers and the transmittance was also the best. As shown in Figure $4 \mathrm{~b}$, the lower the thickness, the better the transparency of the films. The reason was that the thicker films were easy to clip impurities or tiny bubbles in the process, and there were not conducive to solvent volatilization. The higher the yellow value of the film thickness also reduces the transparency of PI to a certain extent. The transparency of pure PI films at $400 \mathrm{~nm}$ was $67 \%(\mathrm{CPI}-315 \mu \mathrm{m}), 37 \%(\mathrm{CPI}-430 \mu \mathrm{m})$, $3 \%(50 \mu \mathrm{m})$, and $500 \mathrm{~nm}$ was $94 \%(15 \mu \mathrm{m}), 93 \%(30 \mu \mathrm{m})$ and $87 \%(50 \mu \mathrm{m})$.

The technology of gradient vacuum could improve the light transmittance, because it could avoid the discoloration caused by the solvent oxidation during the thermal imidization process and could deal with the bubble problem during the synthesis process, it was shown in Figure 4c that the technology of gradient vacuum could improve the light transmittance by about $2 \%$. After the secondary film-forming process after dissolution(CPI-2 $30 \mu \mathrm{m})$ was prepared, the free monomer and colored impurity in the polymer could be effectively removed. It would improve the wavelength of the UV stage and reduce the transmittance of $420 \mathrm{~nm}$ band, which was due to the introduction of a new solvent(NMP) to produce a certain residue in the process of heating secondary film formation. It was shown in Figure $4 d$ that if reducing the thickness of the film, it would greatly reduce the residual solvent NMP. In the film, the transmittance(CPI-1 $15 \mu \mathrm{m})$ could reach $82 \%$ at $400 \mathrm{~nm}$ and the yellowness index is 5.5.

Yellowness index (YI) is used to characterize the yellowing degree of colorless, transparent, translucent or near white polymer materials, which is one of the important optical indexes in resin plastics industry.

$$
\mathrm{YI}=\frac{100(\mathrm{CxX}-\mathrm{CzZ})}{\mathrm{Y}}
$$

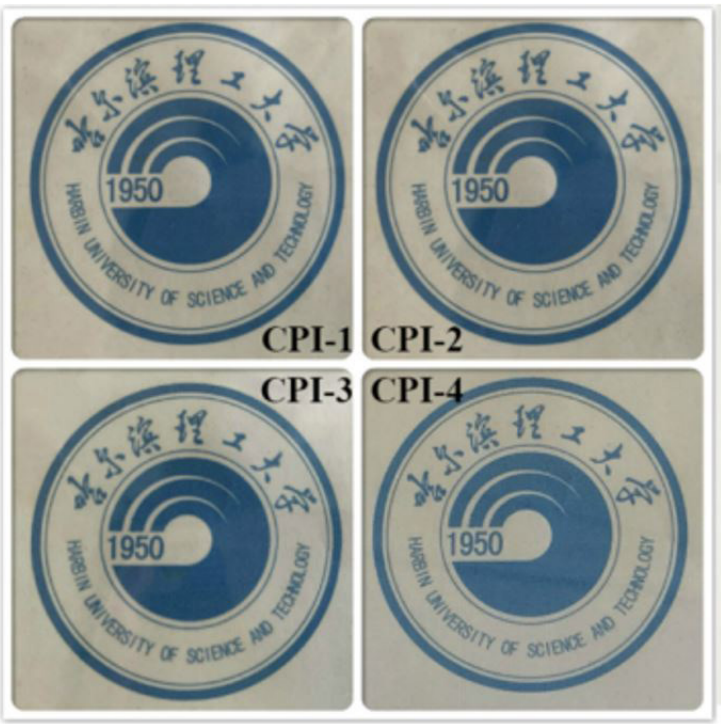

The YI of the PI-(CPI-1 $15 \mu \mathrm{m})$ is 5.5 and the PI-HFBAPP/ PMDA is 78.6. The YI of the film is greatly decreased a lot by structural design and process optimization. As you can see from Figure 5, the yellow effect of the film is not visible at all.

As could be seen from Figure 6, the transparency of the same series of PI films increased with the increase of the $\mathrm{F}$ group ratio. We attribute the reason for the introduction of the side group in the PI chain that destroyed the charge transfer complex(CTC). Increasing the high electronegative group was an effective way to reduce the CTC effect by weakening the intermolecular and intramolecular interactions, reducing the number of free monomers, and introducing large resistance side groups.

\subsection{Thermal performance characterization}

Dynamic thermo-mechanical analysis(DMA) was used to measure the modulus of the material along with the change of temperature, the glass transition temperature of the material in the characterization of molecular chain motion, and molecular inter-atomic forces. The change of loss modulus(E") represented the intensity of the movement of molecular chains. The change of storage modulus( $\left.E^{\prime}\right)$ represented the strength of intermolecular forces.

From the curves of loss modulus( $\left.E^{\prime \prime}\right)$ versus temperature in Figure 7, it could be seen that the peak temperature of the respective loss modulus represented the glass transition temperature, the $\mathrm{Tg}$ of PI-HFBAPP/6FDA was $267{ }^{\circ} \mathrm{C}$, and energy storage density up to $1170 \mathrm{MPa}$. The larger the molecular weight of the material, the more tangles between the molecules. The more heat generated by friction, the greater the storage modulus. After the tangent of the curve, the temperature continued to increase, the value of the storage modulus momentarily dropped to zero, and the modulus decayed completely in the temperature range where the temperature increase was small.

Figure 5. The actual effect of PI film.

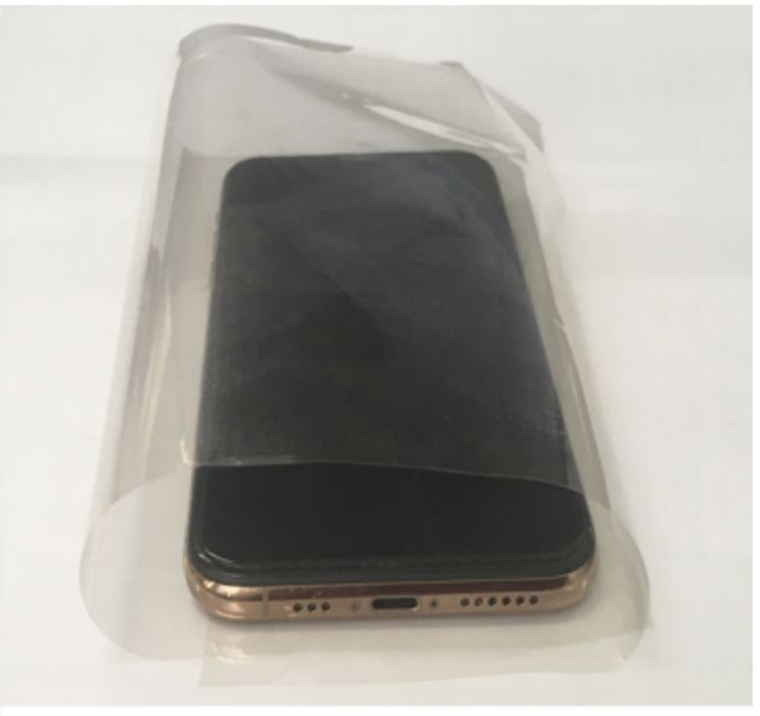




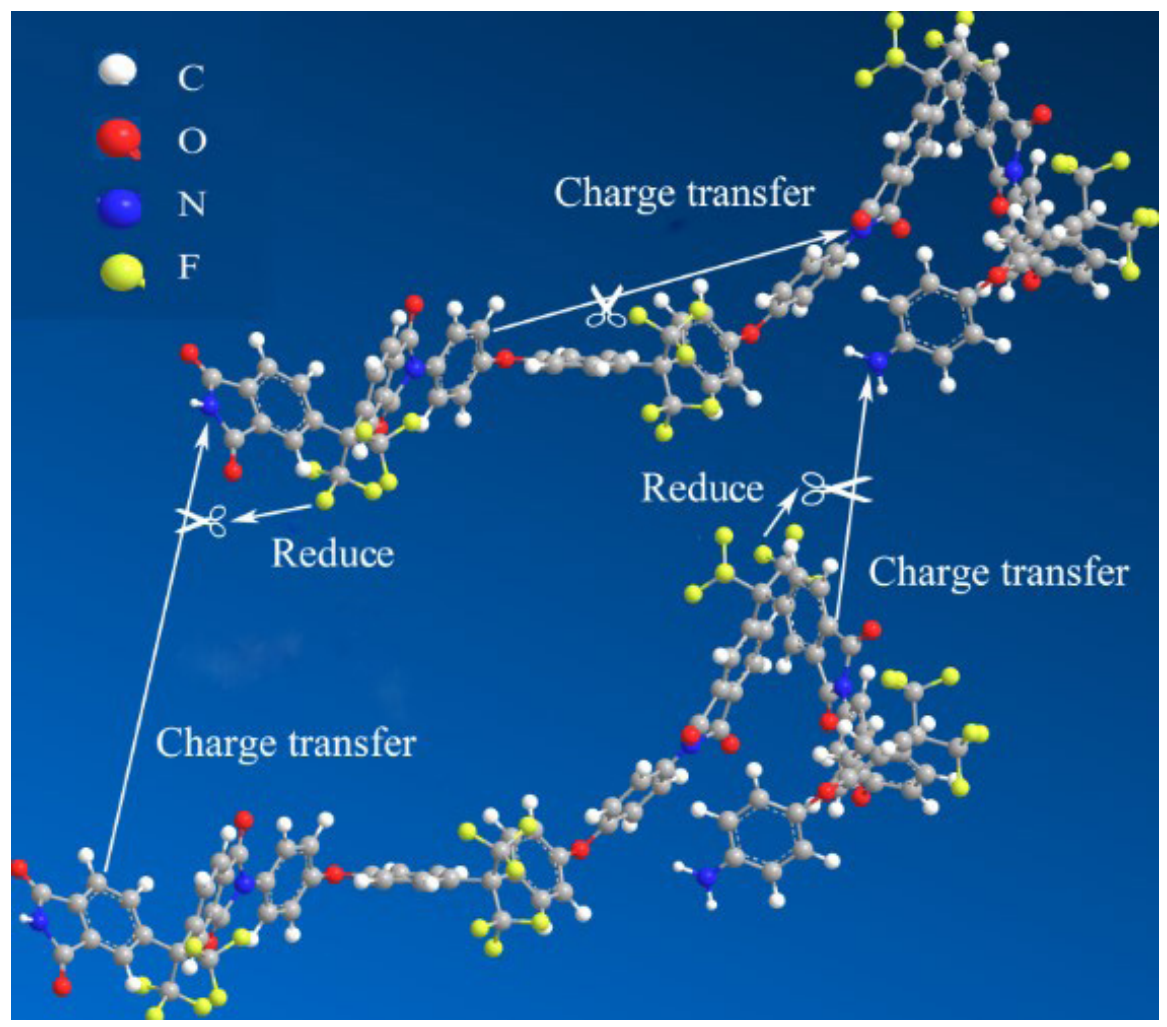

Figure 6. Schematic diagram of the charge transfer of CTC.

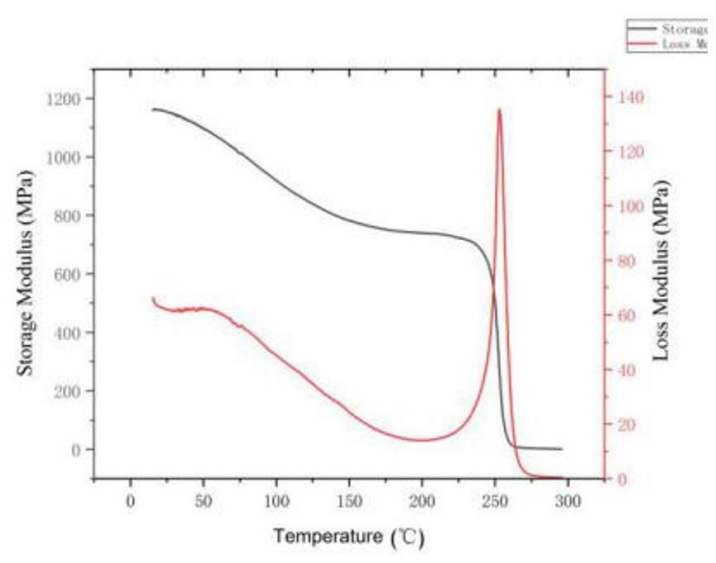

Figure 7. Glass transition temperature and storage modulus of PI composite films.

Thermo-mechanical analysis(TMA) characterized in the case of a certain temperature program, the load force was close to zero. The dimensional variation of the measured sample was functional with temperature or time in isotropic polymers, the molecular chains were promiscuously oriented, and their thermal expansion coefficient strongly depended on the weak intermolecular interactions.

In Figure 8, the thermal expansion coefficient of the films prepared by different processes was different, and the film without doping the filler achieved a more ideal effect. The thermal expansion coefficient of PI-HFBAPP/6FDA cure film was $67 \mathrm{ppm} / \mathrm{k}$. The presence of CF3 resulted in a decrease in the packing density of PI macromolecules, an increase in the free volume of the molecular chain, and a smaller interaction between the molecular chains. Therefore, by adding less $\mathrm{F}$ element would decrease the coefficient of linear thermal expansion. However, the structure with a high content of $\mathrm{F}$ atom was more stable and could be used to prepare films with higher molecular weight. It increased the packing density of molecules and reduces the free space in the same volume. Under the same conditions, the dimensional stability of the film was better. After the process optimization, the thermal expansion coefficient of the PI film increased. The reason was that the molecular weight of the film was lost after the secondary dissolution process, the intermolecular force was reduced, and the heat required to expand the distance between molecules was reduced. For this problem, we could only optimize the process as far as possible to reduce the loss caused by repeated coating. Theoretically, if the process was optimized enough, the thermal expansion coefficient of the second film was expected to be lower than that of the pure film.

\subsection{Characterization of electrical properties}

The dielectric property of the PI films was characterized from $100 \mathrm{~Hz}$ to $107 \mathrm{~Hz}$ and obtained the dielectric constant. Since the dielectric loss was related to the energy dissipation due to the oscillating electric field, it was necessary to select the low dielectric constant and low dielectric loss materials. Since the dielectric loss was related to the energy dissipation due to the oscillating electric field, it was necessary to 

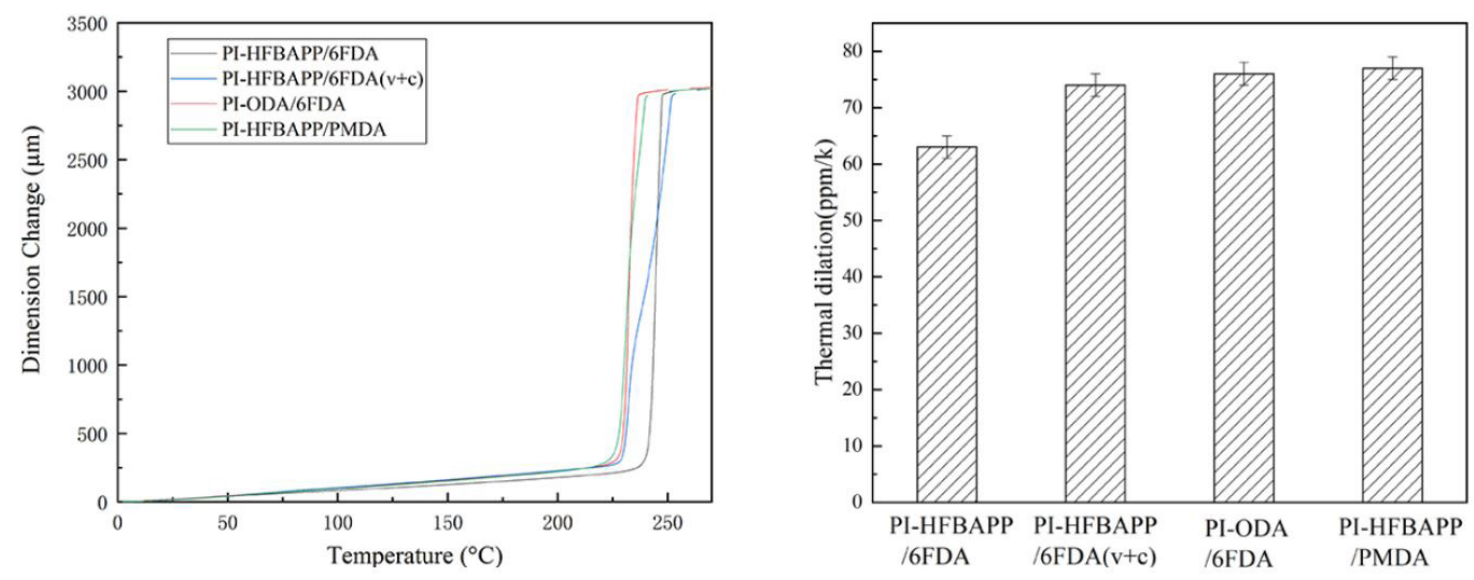

Figure 8. Thermal expansion coefficient diagram of PI film.
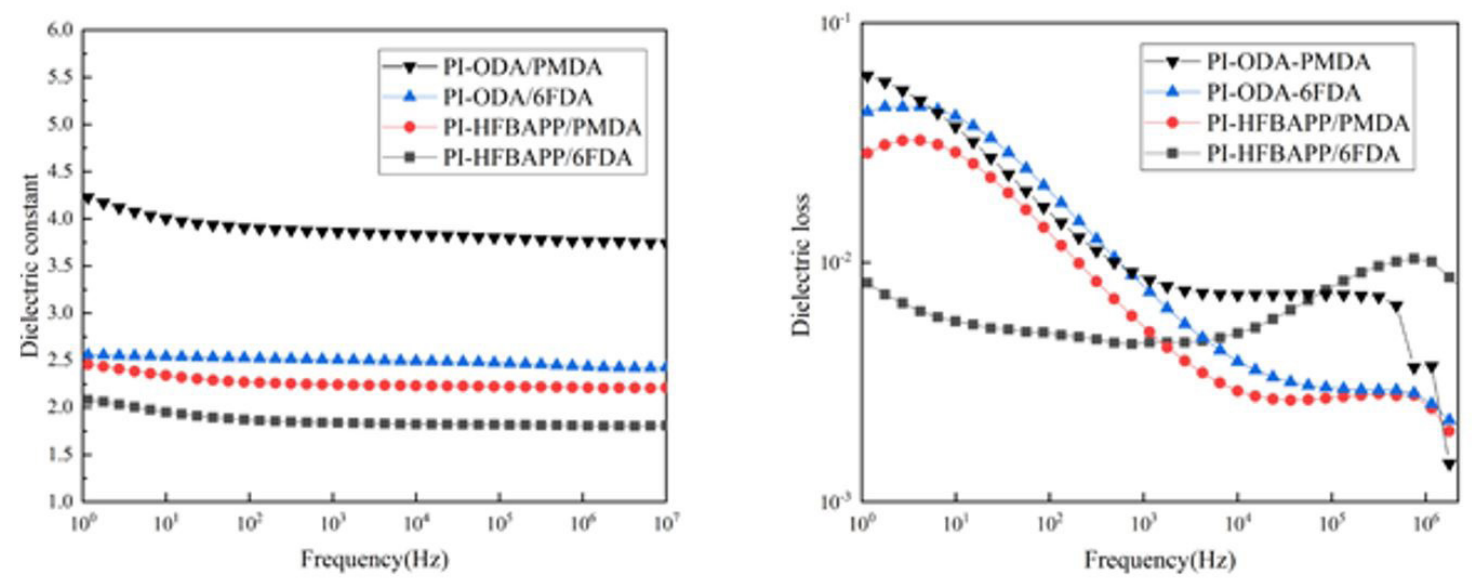

Figure 9. Dielectric properties of PI different films.

select the low dielectric constant and low-dielectric loss materials and longer service life. Accounting to Figure 9, PI-HFBAPP/6FDA had a lower dielectric constant that defeat traditional PI films.

The low-k and the low dielectric were attributed to increasing the spatial group of molecules by adding a $\mathrm{C}-\mathrm{F}$ bond. The $\mathrm{C}-\mathrm{F}$ bond had less dipole polarization. Consequently, the increase of $\mathrm{C}-\mathrm{F}$ bond could effectively reduce the dielectric constant and dielectric loss. The PIHFBAPP/6FDA film with a large number of CF3 groups had an excellent dielectric ability. The dielectric constant of the PI films was 2.1 and the dielectric loss had been below 10-2 at the full frequency band.

The breakdown field strength of the dielectric was the ultimate ability of the dielectric to maintain insulation performance under the action of an electric field. Figure 10 showed the volume resistivity and electrical field strength of PI.

Figure 10 reported the electric field and volume resistivity of the different PI. The prepared F-containing PI film reached $171.3 \mathrm{kV} / \mathrm{mm}$ and the volume resistivity of the four films was characterized. The volume resistivity of PI-HFBAPP/6FDA film was reached $3.3 \times 1015 \Omega / \mathrm{m}$. In general, the dielectric breakdown occurred mainly in the weakest part of the dielectric properties of materials, and the regular structure results in fewer leakage pathways. For pure films, some of the films with the structure with a high content of $\mathrm{F}$ atom would distort the structure to some extent and form weak points, so the breakdown strength would be weaker than that of PI films with benzene structure to some extent. The PI(HFBAPP/6FDA) film with the structure with a high content of $\mathrm{F}$ atom also had a regular structure and the anti-wear loss rate was low, and the charge transfer effect inside the film was very weak. The voltage needs to consume more energy and converted it into heat energy to lose the structure of the film before it could break down at the weak point. The volume resistivity of PI film was mainly related to the intramolecular or intermolecular phase resistance. With the decrease of the internal charge of the polymer, the volume resistivity of the PI film increased, and the insulation performance of the PI film was better. The volume resistivity of the PI composite film showed the same trend as the breakdown field strength. In addition, due to the long distance between the two adjacent particles, the 

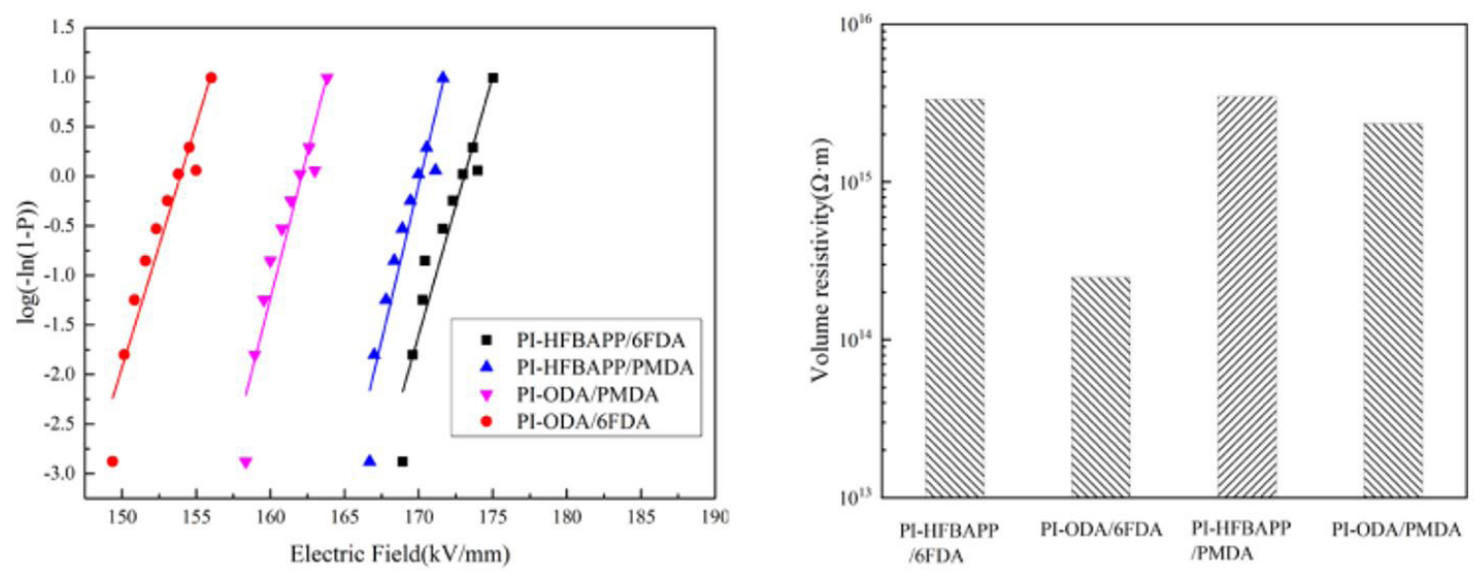

Figure 10. Volume resistivity and Electrical Field strength of PI by different monomers.

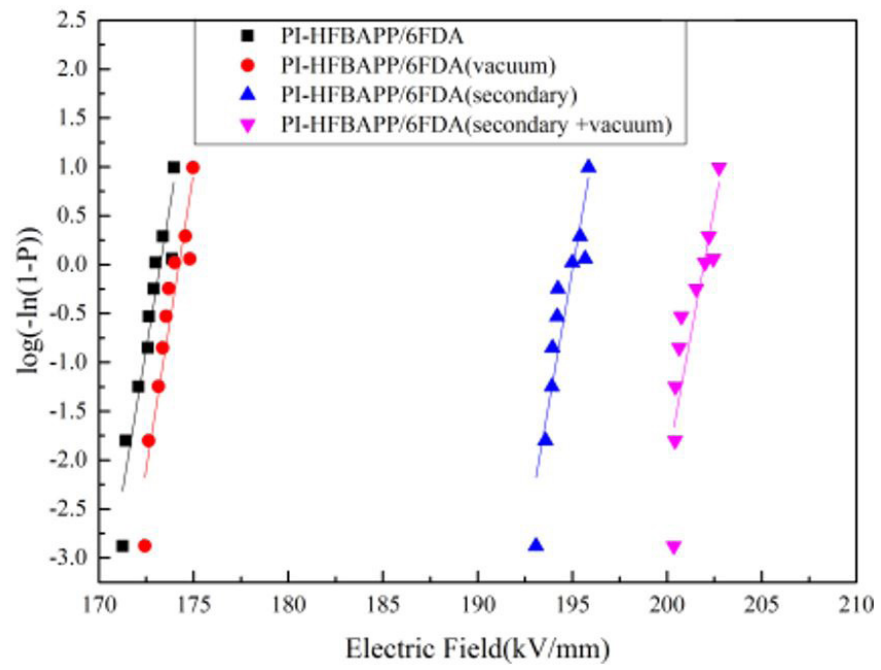

Figure 11. Electric Field of PI films with different process.

barrier which hindered the carrier migration decreases, and the volume resistivity increased.

Figure 11 reported the field strength of the PI obtained by the gradient vacuum treatment and the secondary film formation could reach $202 \mathrm{kV} / \mathrm{mm}$. The reason was that the film defects and the impurities could be effectively reduced during the process treatment process. Gradient vacuum technology could effectively reduce the physical defects in the preparation process of PI films, which made PI films have a smoother surface and a higher degree of the electric field. After dissolution, the residual monomer impurities and other influencing factors could be removed by secondary film formation, and the capacity of the film properties could be further improved. Compared with the film after the gradient vacuum, the PI film after dissolution increased more insulation performance.

\section{Conclusion}

Two series of PI were synthesized by the two-step method from HFBAPP, 6FDA, ODA, and PMDA. Various optimization attempts were made to determine the effect of gradient vacuum and secondary dissolution on the research direction. With the increase of $\mathrm{F}$ content in the film, the effect of CTC was greatly weakened, the transmittance was obviously improved, the dielectric constant and dielectric loss were reduced, and the coefficient of thermal expansion was reduced. The process-optimized PI-HFBAPP/6FDA film reached $82 \%$ at $400 \mathrm{~nm}$ and total penetration at $425 \mathrm{~nm}$. The glass transition temperature was $267^{\circ} \mathrm{C}$ and the storage modulus was $1170 \mathrm{MPa}$. The coefficient of thermal expansion was $67 \mathrm{ppm} / \mathrm{k}$. The film had excellent electrochemical performance, which breakdowns resistance voltage was $5.3 \mathrm{kV}$ and the breakdown field strength was $202 \mathrm{kV} / \mathrm{mm}$. The dielectric constant was 2.1 , the dielectric loss was less than $10^{-2}$ and bulk resistance was $3.3 \times 10^{15} \Omega \cdot \mathrm{m}$. In summary, it effectively inhibits that the CTC action in the polyimide film structure and ensures the other properties of PI by optimizing the process. The PI transparent film had high permeability, excellent heat resistance, excellent dimensional stability, high breakdown field strength, low dielectric constant, and low dielectric loss. The OLED 
commonly used in folding screens have the problems of low melting point and short service life - unlike the PI films. However, this PI film had considerable progress in the transparent film and a good application prospect for the flexible display market. We have achieved good performance in the transparent properties of films and it can be effectively applied to practical improvements.

\section{Reference}

1. Nomura, K., Ohta, H., Takagi, A., Kamiya, T., Hirano, M., \& Hosono, H. (2004). Room-temperature fabrication of transparent flexible thin-film transistors using amorphous oxide semiconductors. Nature, 432(7016), 488-492. http:// dx.doi.org/10.1038/nature03090. PMid:15565150.

2. Lee, J., Lee, P., Lee, H.-B., Hong, S., Lee, I., Yeo, J., Lee, S. S., Kim, T.-S., Lee, D., \& Ko, S. H. (2014). Silver nanowires: room-temperature nanosoldering of a very long metal nanowire network by conducting-polymer-assisted joining for a flexible touch-panel application. Advanced Functional Materials, 23(34), 4171-4176. http://dx.doi.org/10.1002/adfm.201203802.

3. Wang, D., Zhang, Y., Lu, X., Ma, Z., Xie, C., \& Zheng, Z. (2018). Chemical formation of soft metal electrodes for flexible and wearable electronics. Chemical Society Reviews, 47(12), 4611-4641. http://dx.doi.org/10.1039/C7CS00192D. PMid:29722373.

4. Kholmanov, I. N., Stoller, M. D., Edgeworth, J., Lee, W. H., Li, H., Lee, J., Barnhart, C., Potts, J. R., Piner, R., Akinwande, D., Barrick, J. E., \& Ruoff, R. S. (2012). Nanostructured hybrid transparent conductive films with antibacterial properties. ACS Nano, 6(6), 5157-5163. http://dx.doi.org/10.1021/nn300852f. PMid:22519712.

5. Ni, H. J., Liu, J. G., Wang, Z. H., \& Yang, S. Y. (2015). A review on colorless and optically transparent polyimide films: chemistry, process and engineering applications. Journal of Industrial and Engineering Chemistry, 28, 16-27. http://dx.doi. org/10.1016/j.jiec.2015.03.013.

6. Li, P., Ma, J., Xu, H., Xue, X., \& Liu, Y. (2016). Highly stable copper wire/alumina/polyimide composite films for stretchable and transparent heaters. Journal of Materials Chemistry. C, Materials for Optical and Electronic Devices, 4(16), 35813591. http://dx.doi.org/10.1039/C5TC04276C.

7. Moon, K.H., Chae, B., Kim, K., Lee, S., \& Jung, Y. (2019). Preparation and characterization of transparent polyimide-silica composite films using polyimide with carboxylic acid groups. Polymers, 11(3), 489. http://dx.doi.org/10.3390/polym11030489. PMid:30960474.

8. Kwon, S. J., Jang, A. R., Bae, J., Kim, Y. S., \& Lee, S. W. (2013). Preparation and characterization of transparent polyimide composite films for flexible substrate. Journal of Nanoelectronics \& Optoelectronics, 8(6), 588-593. http:// dx.doi.org/10.1166/jno.2013.1525.

9. Damaceanu, M.-D., Constantin, C.-P., Nicolescu, A., Bruma, M., Belomoina, N., \& Begunov, R.-S. A. (2014). Highly transparent and hydrophobic fluorinated polyimide films with ortho -kink structure. European Polymer Journal, 50(1), 200-213. http://dx.doi.org/10.1016/j.eurpolymj.2013.10.030.

10. Xiao, T.-C., Fan, X., Fan, D., \& Li, Q. (2017). High thermal conductivity and low absorptivity/emissivity properties of transparent fluorinated polyimide films. Polymer Bulletin, 74(11), 4561-4575. http://dx.doi.org/10.1007/s00289-0171974-6.

11. Chen, S., Yang, Z., \& Wang, F. (2019). Preparation and characterization of polyimide/kaolinite nanocomposite films based on functionalized kaolinite. Polymer Engineering and Science, 59(s2), E380-E386. http://dx.doi.org/10.1002/ pen.25069.

12. Shams, N., Haghighi, B., \& Rahmati, A. (2006). Prussian blue: electrochemical behavior and operational stability. In $210^{\text {th }}$ ECS Meeting. Cancun, Mexico: Curran Associates, Inc.

13. Mi, Z., Liu, Z., Yao, J., Wang, C., Zhou, C., Wang, D., Zhao, X., Zhou, H., Zhang, Y., \& Chen, C. (2018). Transparent and soluble polyimide films from 1,4:3,6-dianhydro-D-mannitol based dianhydride and diamines containing aromatic and semiaromatic units: Preparation, characterization, thermal and mechanical properties. Polymer Degradation \& Stability, 151, 80-89. http://dx.doi.org/10.1016/j.polymdegradstab.2018.01.006.

14. Tapaswi, P. K., Choi, M. C., Jung, Y. S., Cho, H. J., Seo, D. J., \& Ha, C. S. (2014). Synthesis and characterization of fully aliphatic polyimides from an aliphatic dianhydride with piperazine spacer for enhanced solubility, transparency, and low dielectric constant. Journal of Polymer Science. Part A, Polymer Chemistry, 52(16), 2316-2328. http://dx.doi. org/10.1002/pola.27242.

15. Yu, H. C., Jung, J. W., Choi, J. Y., Oh, S. Y., \& Chung, C. M. (2017). Structure-property relationship study of partially aliphatic copolyimides for preparation of flexible and transparent polyimide films. Journal of Macromolecular Science: Part A - Chemistry, 54(2), 97-104. http://dx.doi.org/10.1080/1060 1325.2016.1261622.

16. Jang, W., Seo, J., Lee, C., Paek, S. H., \& Han, H. (2010). Residual stress and mechanical properties of polyimide thin films. Journal of Applied Polymer Science, 113(2), 976-983. http://dx.doi.org/10.1002/app.29558.

17. Lu, Y. H., Hu, Z. Z., Bian, J. M., \& Wang, Y. F. (2011). Transparent polyimides and their ito flexible conductive film. Advanced Materials Research, 239-242, 1211-1214. http:// dx.doi.org/10.4028/www.scientific.net/AMR.239-242.1211

18. Cheng, S. W., Huang, T. T., Tsai, C. L., \& Liou, G. S. (2017). Highly transparent polyhydroxyimide/tio2 and zro2 hybrid films with high glass transition temperature $(\mathrm{tg})$ and low coefficient of thermal expansion (cte) for optoelectronic application. Journal of Materials Chemistry. C, Materials for Optical and Electronic Devices, 5(33), 8444-8453. http:// dx.doi.org/10.1039/C7TC02819A.

19. Yang, Y., Park, J. H., Jung, Y., Lee, S. G., Park, S. K., \& Kwon, S. (2017). Effect of fluorination on haze reduction in transparent polyimide films for flexible substrates. Journal of Applied Polymer Science, 134(4), 44375. http://dx.doi. org/10.1002/app.44375.

20. Bae, W. J., Kovalev, M. K., Kalinina, F., Kim, M., \& Cho, C. (2016). Towards colorless polyimide/silica hybrids for flexible substrates. Polymer, 105, 124-132. http://dx.doi.org/10.1016/j. polymer.2016.10.023.

21. Jun, J., Lee, J. H., Choi, H. J., Moon, S., Kim, I. D., \& Lee, H. (2017). Fabrication of optically-functionalized colorless polyimide patterns with high durability. Applied Surface Science, 423(30), 881-886. http://dx.doi.org/10.1016/j. apsusc.2017.06.277.

22. Khosa, M. K., Jamal, M. A., Iqbal, R., Muneer, M., Saif, M. J., Zia, K. M., \& Hamid, M. (2017). Thermal stability and mechanical properties of organo-soluble and processable polyimides for high-temperature materials. Polymer-Plastics Technology and Engineering, 56(1), 22-28. http://dx.doi.org/ 10.1080/03602559.2016.1185627.

23. Jo, B. W., \& Ahn, K. H. (2014). The effect of film thickness on the depth-wise chain orientation of rod-shaped polyimide. Journal of Polymer Science. Part B, Polymer Physics, 52(12), 848-857. http://dx.doi.org/10.1002/polb.23498.

24. Liu, L., Cao, C., Ma, X., Zhang, X., \& Lv, T. (2020). Thermal conductivity of polyimide/aln and polyimide/(aln $+b n)$ 
composite films prepared by in-situ polymerization. Journal of Macromolecular Science Part A Chemistry, 57(5), 398-407. http://dx.doi.org/10.1080/10601325.2019.1703555.

25. Wu, G., Li, J., Wang, K., Wang, Y., Pan, C., \& Feng, A. (2017). In situ synthesis and preparation of tio2/polyimide composite containing phenolphthalein functional group. Journal of Materials Science Materials in Electronics, 28(9), 6544-6551. http://dx.doi.org/10.1007/s10854-017-6343-6.

26. Wang, Z. H., Chen, X., Yang, H. X., Zhao, J., \& Yang, S. Y. (2019). The in-plane orientation and thermal mechanical properties of the chemically imidized polyimide films. Chinese Journal of Polymer Science, 37(3), 268-278. http://dx.doi. org/10.1007/s10118-019-2173-8.

27. Lanč, M., Sysel, P., Šoltys, M., Štěpánek, F., Fónod, K., Klepić, M., Vopička, O., Lhotka, M., Ulbrich, P., \& Friess, K. (2018). Synthesis, preparation and characterization of novel hyperbranched 6FDA-TTM based polyimide membranes for effective $\mathrm{CO} 2$ separation: effect of embedded mesoporous silica particles and siloxane linkages. Polymer, 144, 33-42. http://dx.doi.org/10.1016/j.polymer.2018.04.033.

28. Wu, G., Cheng, Y., Wang, Z., Wang, K., \& Feng, A. (2017). In situ polymerization of modified graphene/polyimide composite with improved mechanical and thermal properties. Journal of Materials Science Materials in Electronics, 28(1), 576-581. http://dx.doi.org/10.1007/s10854-016-5560-8.

29. Luo, L., Zhang, J., Huang, J., Feng, Y., Peng, C., Wang, X., \& Liu, X. (2016). The dominant factor for mechanical property of polyimide films containing heterocyclic moieties: in-plane orientation, crystallization, or hydrogen bonding. Journal of Applied Polymer Science, 133(39), 44000. http://dx.doi. org/10.1002/app.44000.

30. Shen, J., Li, F., Cao, Z., Barat, D., \& Tu, G. (2017). Light scattering in nanoparticle doped transparent polyimide substrates. ACS Applied Materials \& Interfaces, 9(17), 14990-14997. http://dx.doi.org/10.1021/acsami.7b03070. PMid:28397490.

31. Cao, C., Liu, L., Ma, X., Zhang, X., \& Lv, T. (2020). Synthesis and properties of fluorinated copolymerized polyimide films. Polimeros: Ciência e Tecnologia, 30(2), e2020017. http:// dx.doi.org/10.1590/0104-1428.10019.

Received: Jan. 14, 2021

Revised: Mar. 03, 2021

Accepted: Mar. 05, 2021 